\title{
Social Learning and Rational-Emotive Education: An Exploratory Investigation of Students' Perspective
}

\author{
Gisela Steins*, Anna Haep \\ Institut für Psychology, Fakultät für Bildungswissenschaften, Campus Essen/Weststadttürme, University of \\ Duisburg-Essen, Essen, Germany \\ Email: "gisela.steins@uni-due.de
}

Received 3 June 2015; accepted 10 July 2015; published 13 July 2015

Copyright (C) 2015 by authors and Scientific Research Publishing Inc.

This work is licensed under the Creative Commons Attribution International License (CC BY). http://creativecommons.org/licenses/by/4.0/

c) (7) Open Access

\begin{abstract}
There is no doubt about the relevance of social learning from the perspective of many groups of adults, such as teachers and researchers. However, do students share this evaluation, especially if students are socially disadvantaged? The current study explored whether rational-emotive education (REE) was a suitable concept for social learning with disadvantaged students and what to consider when students' perspective was involved. Mixed methods were used. Social problem solving was explored with a pre-post design in three groups (Social learning Treatment, Control, and Follow-Up: Social learning Treatment after one year) of 239 seventh and eighth graders. The attitudes of the students in the Treatment Group toward the usefulness of social learning played a crucial role in social problem solving. The reasons for the variance in students' attitudes were subjected to a content analysis. A key finding was that students expected more entertainment and less formal education so that more effort was needed to motivate students at the beginning of a curriculum. In addition, most students appreciated the opportunity to learn a self-technology such as rational-emotive behavior therapy (REBT) as core element of REE.
\end{abstract}

\section{Keywords}

Social Learning, Rational-Emotive Education, Students' Attitudes, Social Skills

\section{Introduction}

There is no doubt about the relevance of social learning from the perspective of many groups of adults, such as

${ }^{*}$ Corresponding author. 
teachers and researchers. Many programs are dedicated to improve students' social and emotional skills as the Child Development Project (Solomon, Battistich, Watson, Schaps, \& Lewis, 2000) and many other projects are summarized by Elias and Schwab (2006). Schools try to support the development of students as responsible citizens after graduating. Students are expected to have learned to deal responsibly with their own lives and those of others and at least to have social skills, "an awareness of, and ability to manage, emotions in an age- and context-appropriate manner” (LeBuffe, Shapiro, \& Naglieri, 2009, cited by Fleming, Mackrain, \& LeBuffe, 2013: p. 387). These expectations are rooted in a long tradition and can be already found by von Humboldt as one of the first protagonists to stress education for all people as a value in itself (von Humboldt, 1809). "There is certain knowledge that must be general, and even more a certain formation of attitudes and character that cannot be missing." (von Humboldt quoted by Spitta, 2006: pp. 45-46; translated by the author). For a long time, von Humboldt's ideas of education determined an image of an ideal teacher as a person who “...was required to know how to define goals like critical citizenship, political responsibility, individual liberation, and emancipation and to outline ideas about how to reach these goals in school” (Blömeke, 2006: p. 322).

The effects of social learning become visible when such programs start early and are implemented over a long period of time. But even then, their effects can still fade quickly (Hattie, 2009).

One reason for small effects can be found in implicit teaching. Even schools that have the highest behavioral standards for their teachers (mindfulness, gender competence, intercultural competence, friendliness, awareness, rational language, a willingness to discuss, etc.) cannot successfully pass social skills on only implicitly. Studies have shown that the explicit and direct teaching of content is important for students' development of stable knowledge and skills (Donovan \& Radovich, 1998, 1999; Kirschner, Sweller, \& Clark, 2006; Hattie, 2009). This fact suggests that it is important to make social learning explicit for adolescents.

In addition, social learning like social education is associated with ill-defined concepts such as social skills, emotional skills, morality, and others (Hattie, 2009). This conceptual fuzziness promotes the filling of social learning with any content that can be loosely associated with anything "social". Social learning is a fundamental area of general psychology and social psychology that deals with the fact that people learn values and norms from models in their environment and through synchronization with the social environment (Hatfield, Cacioppo, \& Rapson, 1994). By contrast, in the sense in which the term is used here, social learning involves a normative ethical framing. It refers to the skills that enable people to behave reasonably in a social context, to understand this context, and to be able to reflect on it critically. To distinguish between what is right and wrong and to behave accordingly requires perpetual critical reflection and discussion. Successful social learning requires the mastery of a set of social skills such as perspective taking, empathy, social problem solving, critical reflectivity, communication skills, self-regulation, and a high tolerance for frustration. All these abilities are developed in a social context, but not by themselves and not automatically. Thus conceptual fuzziness may be a reason of small effects.

\section{Social Learning from a Rational-Emotive Perspective}

We developed a social learning program which met some important recognitions: The teaching is explicit and continuous and the frame of reference meets scientific criteria. As frame of reference we choose Rational-Emotive Behavior Therapy (REBT) and the applied Rational-Emotive Education (REE).

REBT is a theory whose theoretical and philosophical context is dedicated to the establishment and maintenance of mental health. Like all humanistic approaches, the individual is at the center of attention. A special feature of REBT has always been the idea that the individual is not independent of the social context, but is also responsible and has degrees of freedom. Through scientific thinking, the value of thinking is strengthened as a means for recognizing the world and its reflection. It is clearly evident that REBT can be used to strengthen the components of social skills within a scientifically oriented frame of reference (Dryden, 2012; Ellis, 1994; Vernon, 1996, 2002) as REBT uses scientific evidence to emphasize its orientation toward reality.

REBT can therefore be applied to sharpen the content of as well as to implement social learning as REBT has been widely used with children and young people, for example, in the context of therapy (Adomeh, 2006; Flanagan, Korrie, \& Henry, 2010; Gonzalez, Nelson, Gutkin, Saunders, Galway, \& Shweny, 2004), school psychology (DiGiuseppe \& Bernard, 1990), education (Kachman \& Mazer, 1990; Sapp, 1996; Sharp \& McGollum, 2005; Trip, Vernon, \& McMahon, 2007; Vaida, Kallay, \& Opre, 2008), and school performance (Shannon \& Allen, 1998).

REE was developed by transferring the knowledge of REBT to educational fields. Such methods consist of 
both curricular programs (Vernon, 2002) and specific programmatic material for Anger Management (Flanagan et al., 2010; Sharp et al., 2005) or advancement in mathematics (Shannon et al., 1998). There are also methods that, with the aid of imagination, show children that they can influence their own behavior and feelings (e.g., Garcia \& Pellegrini, 1974; Waters, 1980). REE is taught in a rational manner and sets clear behavioral standards for the teacher (Haep, Steins, \& Wilde, 2012; Knaus, 1974). The emphasis on scientific reasoning strongly promotes judgment and reflectivity. The outstanding feature of an REE-based approach is the great epistemological advantage for students. The systemic core model of REBT (Activating Events-Beliefs-Consequences) is easy to learn, and it ensures independence from the teacher. The central insight is that people have freedom because they have control over their own interpretations of events. This inevitably entails all matters affecting other central concepts of REBT, namely, questions about a person's self-esteem and the ability to tolerate frustration. More than a restriction on social skills, REBT and REE thus strengthen what may be described as cultural techniques. Cultural techniques officially include skills such as language and writing but not the ability to deal with the self, others, and the world.

\section{Aims of the Present Study}

\section{Students' Attitudes toward Social Learning with REE}

In this paper, we explore the influence of disadvantaged students' attitudes on the effects of a rational-emotive social learning program. As far as we know there is a lack of research according to the role of students' attitudes for improvement in social learning. Although teachers are important models for their students, and teachers social skilled behavior have been found to exert very high preventative and beneficial developmental effects on disadvantaged students (Hamre \& Pianata, 2001, 2005; Liew, Chen, \& Hughes, 2010), students may not see that own social skilled behavior may be useful or beneficial.

In the present study, we primarily addressed the question of whether adolescents value this form of social learning curriculum and accept and rate the content as useful. The following study focused on the attitudes of adolescents toward social learning in a socially problematic context. With this research, we aimed to fill a specific gap: Despite there being no doubt about the relevance of social learning from the perspective of many groups of adults, the effectiveness of social learning has often been found to be small (in terms of effect sizes at the group level) and to fade very quickly (Hattie, 2009). In our preliminary studies, there was always the strong impression that, at least in part, disadvantaged students had some strong reservations about educational content of any kind. Hence, two exploratory questions were addressed in this study: a) Can disadvantaged students transfer the content of a social learning curriculum, taught by rational-emotive principles, to certain problematic school situations? (social problem solving), and b) What role do students' attitudes toward social learning play in this transfer?

\section{Method}

\subsection{Setting}

Our work focuses on the effects of REE in comprehensive schools in urban areas where students are particularly disadvantaged. We are dealing with students whose parents, for various reasons, do not educate their children how to deal adequately with themselves or others. These adolescents' access to the world is often very limited as they have very few real-life experiences, and their free time is spent with the contents of highly prefabricated media. The students often do not have an age-appropriate tolerance for frustration. Other skills such as reading and writing are not age-appropriately developed, thus leading these students to be selected for comprehensive schools. Accordingly, many teachers at these special schools are under a great deal of stress (Rushton, 2000). They have to cope with almost the same class sizes as the teachers of students with age-appropriate skills. Teachers at these schools have to deal with a high rate of classroom disturbances and with a strong lack of interest in school content that the students do not conceal.

For the entire school year, eight classes of seventh graders at a comprehensive school from the Ruhrgebiet region of Germany were given a weekly 90-min lesson in social learning. The school is attended only by students who were previously identified with significant cognitive, social, or emotional problems in school. The students' parents often have poor socioeconomic resources. A consequence is that the school has a bad reputation in the region so that presently, there is no hope for a more heterogeneous mix of students. This situation motivated the 
school administrators to contact our research group in order to obtain a partner who could contribute to the explicit social learning of the students with the goal of improving the students' social skills. Further goals were to teach the students how to interact more peacefully and to help replace the school's reputation as a place for violent and aggressive students with a more positive reputation.

\subsection{Sample and Design}

In the present study, a total of 375 students (203 male, 54.1\% and 172 female, 45.9\%) with an average age of $M=$ 13.14 years $(S D=.08$; 7 th graders $M=12.71, S D=.71$; 8th graders $M=13.57, S D=.65$ ) voluntary participated. $70 \%$ of students' families have a history of migration, most of them from Turkey. All students speak German. A total of 178 students had to be excluded from the analysis because they were either absent during one of the two measurement points, their questionnaires were incomplete, or their teachers failed to return the questionnaires. A total of 239 students stayed in the sample (7th graders: 107 male, 54.9\% and 96 female, 53.3\%; 8th graders: 96 male, $53.3 \%$ and 84 female, $46.7 \%)$.

We choose a mixed method design (Creswell, 2014; Patton, 2002) with quantitative data on the one hand and a qualitative analysis of students' attitudes on the other hand. Teachers administered a questionnaire for social learning within a pre-post design (see Figure 1 for an overview about the design). The 239 students were comprised of 108 seventh graders who were given the social learning curriculum (Treatment Group, TG) and 89 eighth graders. Of the 89 eight graders 51 students served as a Control Group (CG). 38 eight graders formed a Follow up Group (FUG), which consisted of students that had already followed the series of lessons for 1 school year. The first time the survey was administered was when the lessons began (T1) at the beginning of the new school year, and the second time the survey was administered was after the lessons ended at the end of the school year (T2).

\subsection{Procedure}

For an entire school year, students are given a class (90 min each week) on social learning. Courses are taught in smaller groups (about 15 students per group) and by two students who are enrolled in teacher education (teacher students). The teacher students are given a basic knowledge of REBT and REE and are monitored in the classroom by their teacher educators. They receive regular feedback on their interactions with regard to rationality, friendliness, and clarity. This level of action is intertwined with another project, REBT in teacher education, which will not be mentioned here.

In the series of lessons, the typical age-appropriate contents of REBT are provided: emotion recognition, emotion origin, body and emotion, thinking and emotion, emotion and behavior, anger as an example for the origin and regulation of emotion, behavior in critical social situations (Haep, Steins, \& Wilde, 2012; Wilde, 1997). These contents are taught and practiced using role playing, group games, and individual work in the form of cognitive exercises. We followed the advices of Bernard as for example using diagrams to illustrate the relationship among activating events, thoughts, and behavior (Bernard, 1990).

The introduction of a system of sanctions is important. As a teacher student begins teaching, a limited number of rules of conduct are presented to the students. The rules are acknowledged and personally committed to by the signatures of the students and the teacher students (Steins, 2014). It is important that these rules are concrete

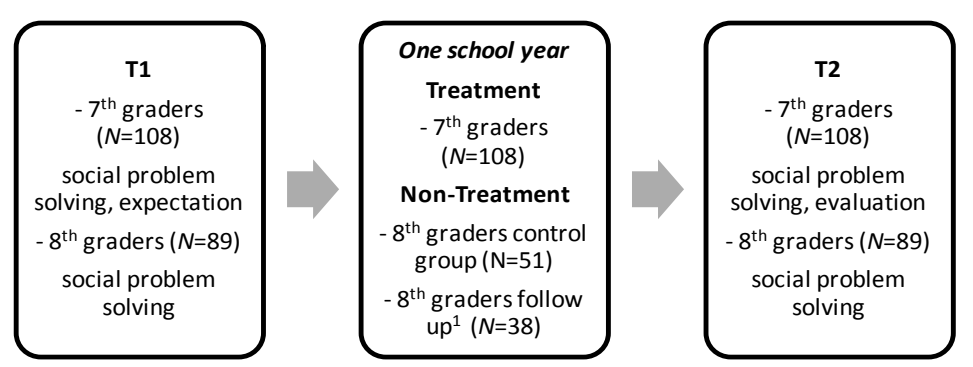

Figure 1. Design of the study. ${ }^{1}$ These students followed the treatment one year before; T1: 375 students; Drop out to T2: 178 students; students staying in the design: 239 students. 
and behavioral. The rules are followed by the consequences of compliance and noncompliance. These rules form the basis of weekly self-reflection and feedback. At the end of a unit (each week), each student indicates how well he/she behaved in accordance with the agreed-upon rules with the symbols + (performed by the rules), (did not follow the rules well enough), or +- (on the whole, sometimes performed by the rules and sometimes was not good enough) and a short explanation. At the beginning of the next lesson, the students' assessment is compared with the assessment and justification of the teacher student. Two plusses can make up for a minus. This possibility of compensation increases the acceptance of feedback (Brehm \& Brehm, 1981; Duval \& Silvia, 2009).

In the beginning, the feedback always leads to many questions. The questions stop quickly when a joint understanding is reached. Discrepancies between the teacher students' and students' perspectives can increase the students' motivation to reduce such discrepancies and can lead to changes in behavior (Higgins, 1987), especially when a student's relationship with the teacher is positive. By the middle of the school year and at the end of the school year students were invited to go on a joint excursion. The joint excursion could be taken for granted and was performed with all students, regardless of their behavior. However, students with poor social skills were given more intensive teaching in very small groups (three students per group). The establishment of these so-called intervention groups appeared to work. However, a systematic evaluation on the effectiveness of the intervention groups is still pending. At the end of the semester or school year, all students received one of three reviews on their performance: "participated," "participated with success," or "participated with great success.” Each student also received a detailed explanation of the evaluation and specific instructions for future behavior.

\subsection{Survey Instruments}

Solving social problems. Previously administered standardized questionnaires had been found impracticable with such samples of adolescents due to language and attention problems. Hence, for this study, we tried to construct a very simple version of a behavioral questionnaire. A set of 10 questions described two social situations that tend to occur frequently. The first situation was: "Imagine a classmate insults you with words. What will you do?” Students were then presented with five qualitatively different approaches that could be divided into negative and positive solutions (Negative solutions: "I insult him back"; "I hit"; "I offend another student out of frustration"; Positive solutions: "I go to the teacher and complain”; "I explain to the classmate why I want him/her to refrain from this behavior"), to which students were asked to apply a 5-point scale to indicate their degree of approval ( 1 = I most certainly do not do this, 5 = I most certainly do this). The second situation was: "Imagine a classmate interrupts the class for the entire teaching period and you cannot concentrate. What will you do?” Three negative solutions were offered: "I bother him back”; "I pinch him”; "I complain to the teacher.” The positive solutions were: "I ask him earnestly to desist from interfering"; "I try to find a solution with him after class so that it does not happen again.”

Attitudes: Expectations and evaluations of the student. On the second survey (T2), the treatment group was asked three further questions: “Did you learn something useful in Social Learning?” (answers ranged from 1 = never to 5 = often); "Do you think the material you learned will help you better manage difficult situations?" (answers ranged from 1 = definitely not to 5 = with certainty); and "How satisfied were you with how the Social Learning class was taught?” (answers ranged from 1 = very dissatisfied to 5 = very satisfied).

The seventh-grade students were also asked to freely express themselves at both time points. At T1, they were asked about their expectations for the series of lessons on Social Learning. At T2, they were asked to evaluate the lessons in their own words.

\section{Results}

\subsection{Solving Social Problems}

Data preparation. The quantitative data were entered into a data processing program (SPSS version 21). The different content blocks were tested for internal consistency. Different indices were created for the two situations. The positive solutions were consistent (T1: $\alpha=.66$; T2: $\alpha=.73$ ), and the negative solutions were consistent as well (T1 $\alpha=.60 ; \mathrm{T} 2: \alpha=.66)$.

The pre-post design. We computed a repeated-measures ANOVA to test the effects on the two situation in- 
dices from the repeated measure of time (T1 and T2) and the between-groups factor of the student groups (TG, FUG, and CG). The analysis showed that the groups were significantly different, $F(4,472)=6.86, p<.001$ (see Table 1). However, there was no effect of time from T1 to T2, nor was there a significant interaction. Post hoc analyses showed (Scheffé $p<.05$ ) that the TG students differed significantly from the two eighth-grade groups insofar as they agreed less with the positive solutions and agreed more strongly with the negative solutions. The FUG and CG students did not differ significantly from each other.

Associations with the teaching evaluations. In a second step, we calculated whether the evaluation of the course as useful was associated with the self-reported reactions to the social problems. The last three questions on the T2 survey were combined into an overall assessment of the seventh graders' perceived usefulness of the lessons $(\alpha=.84)$. A median-split was applied (median $=3.3$ ) so that we could differentiate between the students who perceived the lessons as rather not useful $(N=57)$ and the students who perceived the lessons as rather useful $(N=64)$. The eighth graders were treated as one group, and we computed a repeated-measures analysis on the two social problem indices by time (T1 and T2) and group: eighth graders (CG), seventh graders with low usefulness ratings (TGLU), and seventh graders with high usefulness rating (TGHU). The results showed significant differences between the groups, $F(44,360)=2.60, p<.001, \eta 2=.24$. Table 2 shows that the TGLU students differed significantly from both the TGHU students and the CG students.

Table 1. Pre-post design—positive and negative solutions for social problems.

\begin{tabular}{|c|c|c|c|c|c|c|c|c|}
\hline & \multicolumn{4}{|c|}{ Positive Solutions } & \multicolumn{4}{|c|}{ Negative Solutions } \\
\hline & TG & CG & FUG & General & TG & CG & FUG & General \\
\hline \multicolumn{9}{|c|}{$T 1$} \\
\hline$M$ & 2.76 & 3.24 & 3.05 & 2.95 & 1.99 & 1.99 & 1.88 & 1.90 \\
\hline$S T D$ & 0.95 & 1.00 & 0.74 & 0.96 & 0.76 & 0.65 & 0.51 & 0.70 \\
\hline$N$ & 128 & 73 & 38 & 239 & 128 & 73 & 38 & 239 \\
\hline \multicolumn{9}{|c|}{$T 2$} \\
\hline$M$ & 2.60 & 3.00 & 3.05 & 2.79 & 2.15 & 1.76 & 1.73 & 1.96 \\
\hline$S T D$ & 0.93 & 0.94 & 0.80 & 0.93 & 0.71 & 0.76 & 0.50 & 0.73 \\
\hline$N$ & 128 & 73 & 38 & 239 & 128 & 73 & 38 & 239 \\
\hline
\end{tabular}

TG: Treatment Group; CG: Control Group; FUG: Follow Up Group (social learning program was passed previous school year); Possible Range of answer: 1 - 5; The higher the score, the stronger the agreement for solutions.

Table 2. Positive and negative solutions and rated usability of social education.

\begin{tabular}{|c|c|c|c|c|c|c|c|c|}
\hline & \multicolumn{4}{|c|}{ Positive Solutions } & \multicolumn{4}{|c|}{ Negative Solutions } \\
\hline & TGLU & TGHU & CG & General & TGLU & TGHU & CG & General \\
\hline \multicolumn{9}{|c|}{$T 1$} \\
\hline$M$ & 2.55 & 2.94 & 3.17 & 2.96 & 2.08 & 1.86 & 1.80 & 1.88 \\
\hline$S T D$ & 0.98 & 0.91 & 0.92 & 0.97 & 0.82 & 0.70 & 0.61 & 0.70 \\
\hline$N$ & 57 & 64 & 111 & 232 & 57 & 64 & 111 & 232 \\
\hline \multicolumn{9}{|c|}{$T 2$} \\
\hline$M$ & 2.21 & 2.95 & 3.02 & 2.80 & 2.34 & 1.99 & 1.75 & 1.96 \\
\hline$S T D$ & 0.83 & 0.88 & 0.89 & 0.93 & 0.79 & 0.63 & 0.69 & 0.74 \\
\hline$N$ & 57 & 64 & 111 & 232 & 57 & 64 & 111 & 232 \\
\hline
\end{tabular}

TGLU: Treatment Group Low Usability of Social Education; HGLU: Treatment Group High Usability of Social Education; CG: Control Group. 
They indicated strong agreement with the more negative aspects of problem solving and weaker agreement with the constructive solutions to problems. Furthermore, there was a within-group effect, $F(22,179)=1.81, p<.05$, $\eta 2=.18$. The TG students showed a slight increase in agreement with the negative solutions, whereas the CG students did not show such a change. The TGLU and CG students both showed a slight decrease in agreement with the positive solutions. This decrease in agreement was particularly strong for the TGLU students. Finally, a significant interaction between group and time of testing emerged, $F(44,360)=1.48, p<.05, \eta 2=.15$. The response pattern for the TGLU students was comparatively more pronounced (see Figure 2 and Figure 3).

\subsection{An Analysis of Attitudes toward Social Learning}

Qualitative evaluation. We analyzed the open responses of the seventh graders in order to develop a better understanding of their attitudes. To this end, the program MAXQDA was used, and two experts coded the responses. First, the expectations for the lessons (T1) and the evaluative descriptions (T2) were content coded as negative, neutral, or positive. As a result, six groups of students were identified: Three groups of students who had no changes in their neutral, positive, or negative attitudes and three groups of students whose attitudes changed by becoming neutral, negative, or positive. Neutral statements generally contained no statements that revealed a critical or positive attitude toward the lessons. An example of a student who had become neutral was:

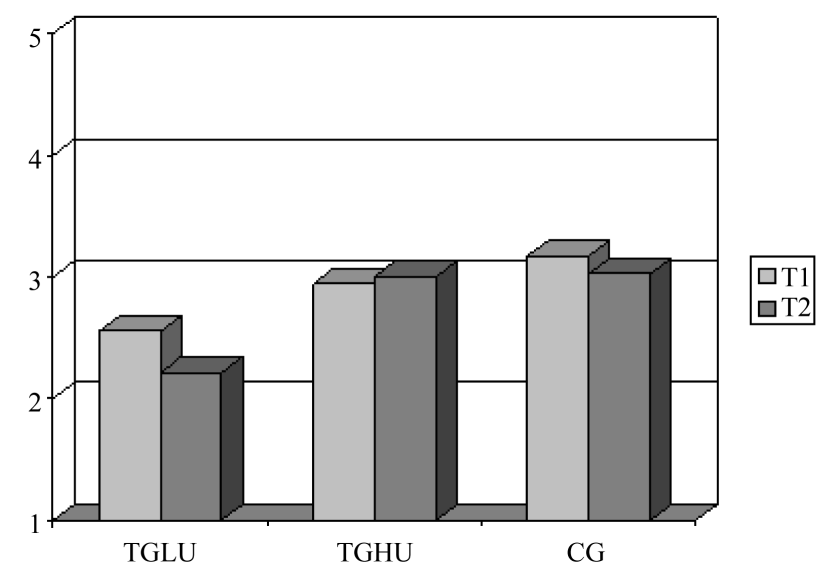

Figure 2. Usability of social education and positive solutions. TGLU: Treatment Group-Low Usability of Social Education; TGHU: Treatment Group-High Usability of Social Education; CG: Control Group.

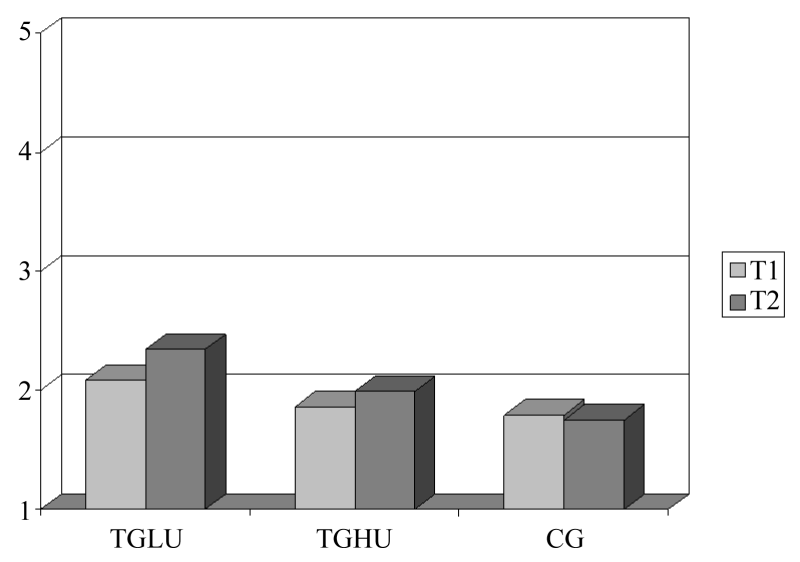

Figure 3. Usability of social education and negative solutions. TGLU: Treatment Group-Low Usability of Social Education; TGHU: Treatment Group-High Usability of Social Education; CG: Control Group. 
“The fact that it is quiet, respectful, no bullying!!!” (T1; positive expectation) and "I would be happy if it was not always so loud and then other are quiet” (T2). This example is prototypical because many changes were from positive to neutral statements. An example of a student who remained neutral included the following statements: "I think it's medium" (T1) and "The fact that we no longer have to stay until 16 clock" (T2). A positive change in attitude can be exemplified by the following statements: "I would not vote because it's unnecessary!" (T1), "I've learned in social learning that you should have respect for other people. That one should not take one's mad mood out on others because it does not work. That if you have a problem with friends, you can talk about it. One should never insult or hurt friends. The social learning has sometimes been fun. I've learned a lot and I took it to heart because it might be important for life" (T2). The group of students who remained positive can be exemplified by the following statements: "I think it's good that I and the others do learn how to behave in such a situation. That one does not hurt, if something does not fit" (T1), "So I think the social learning was useful because, in the class, something has improved. I found the teachers also very nice, it was fun" (T2). Students whose evaluations had turned for the worse formulated statements such as "That'll all be nice!" (T1) and "Social learning is a waste of time!" (T2). Statements that are prototypical for the group of stable negative attitudes read, for example, "Social Learning is shit because I do not need a sense of training" (T1), and "I do not care" (T2).

Contents of the expectations and evaluations. The contents of $\mathrm{T} 1$ and $\mathrm{T} 2$ were exhaustively categorized by two experts. The coding of the transcribed material was based on the expectations (T1) and evaluations (T2). The theoretical approaches of Grounded Theory (Glaser \& Strauss, 1967) were primarily used for the inductive procedure of the coding and analysis of the subcategories of the interview material (Patton, 2002). The core category of the content analysis was the students' attitudes toward the teaching unit. According to Schreier (2014), in particular, the respective subcategories were obtained inductively by processing the material. Inconsistencies between the experts were resolved through discussion.

Quantification of the changes in attitude. To quantify the attitudes in a first step, we calculated the proportions of negative, neutral, and positive attitudes. As can be seen in Table 3, the positive expectations (T1) outweighed the positive evaluations (T2). The number of students who had positive expectations at T1 was higher than the number of students who expressed positive comments at T2, whereas the proportion of students who expressed neutral or negative feedback increased. Figure 4 provides an overview of the distribution of changes in attitude.

These groups of students who showed a negative shift (positive-neutral; positive-negative, neutral-negative; representing $17.3 \%$ ) were particularly interesting. These students displayed a significant loss in motivation. Nine of these students formulated very general evaluations such as "I do not care," from which no further information could be gained. Six students found the class too boring. Three students had expected more trips and found it too loud during class. Two students were happy that the lessons were over because then they could go earlier home. The late hour of the lessons was criticized by one student. In one case, a student complained about changing teachers (in one class, there was increased turnover due to health reasons) and that the contents were too person$\mathrm{al}$ and were too illogical. One student complained about too many worksheets.

The reasons for a positive shift (neutral-positive and negative-positive) of 11 students were related to the usefulness of the material. Four students emphasized the fun that they had. One student emphasized that the teacher helped him a lot.

\section{Discussion}

The results provided the following answers to the questions: a) Yes, the content of a curriculum social learning, mediated by rational-emotive principles and content, can be transferred to certain problematic school situations;

Table 3. Frequencies and proportions of positive, negative and neutral attitudes toward social education (T1, T2).

\begin{tabular}{|c|c|c|c|c|}
\hline \multirow[b]{2}{*}{ Attitude } & \multicolumn{2}{|c|}{$\mathrm{T} 1$} & \multicolumn{2}{|c|}{$\mathrm{T} 2$} \\
\hline & $f$ & $\%$ & $f$ & $\%$ \\
\hline Positive & 70 & 66 & 58 & 54.7 \\
\hline Negative & 13 & 12.3 & 19 & 17.9 \\
\hline Neutral & 23 & 21.7 & 29 & 27.4 \\
\hline
\end{tabular}




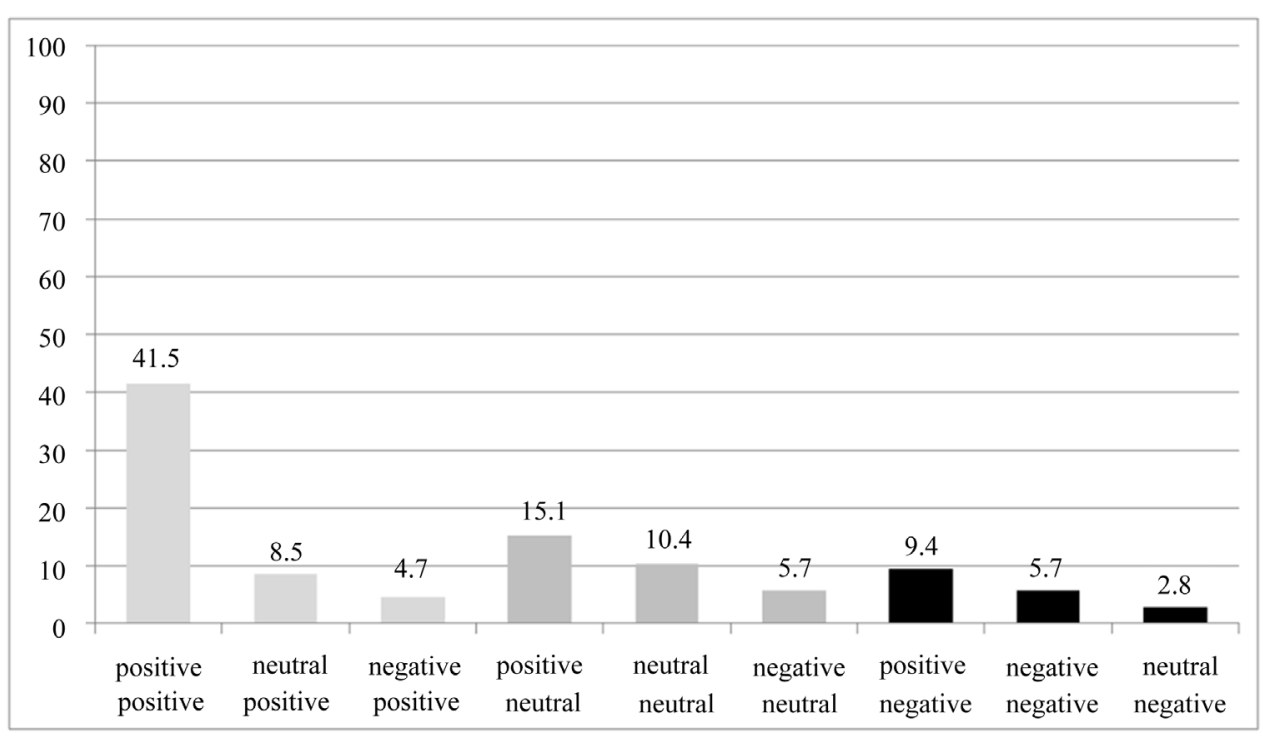

Figure 4. Changes of attitude toward social education in percent.

however, b) only if the students are motivated and if the benefits of the social and educational contents were previously acknowledged. REE is suitable as a method and for providing content for social learning.

However, the results also showed other aspects that are relevant for social learning especially with the help of REE. They represent a typical pattern of findings in research on the effectiveness of social education programs: Even strong effects (Cohen, 1988) and visible learning (Hattie, 2009) at the group level fade quickly. From this, we can draw several conclusions, namely, that such programs are ineffective in the long run, or, that they are better when they are explicit and continuous and, in accordance with the results presented here, that they have to be highly motivating. Students' expressions about the lack of interesting teaching indicate that improvements are needed in teaching. Many students seem to expect that subjects that do not correspond to a classical educational canon should be entertaining. It is certainly important to include this feedback in the teaching process. Although we combined content with games in every lesson, the course content itself often seemed to be dry. One strength of the REE is that it contains systematic knowledge, but this may simultaneously be a weakness because more of a time investment is needed to convey this knowledge. However, the qualitative analysis paints a more complex picture: For the vast number of students who valued the curriculum despite having negative expectations, this was due to the usefulness of the content. This point should be given more recognition.

Overall, the results show that the effectiveness of the curriculum at the group level is visible and that a subgroup of students values the curriculum very much. In addition, the largest group of students both conveyed positive expectations and concluded with positive evaluations. It is also important to appreciate that, of course, for such students, these lessons were seen as valuable in and of themselves insofar as the students' positive attitudes were strengthened by the existence of an explicit social learning.

\subsection{Methodological Reflections}

Because of students poor reading and writing skills only a small self-report were investigated. Only a few students indicated that too many questionnaires were submitted. This makes sense, of course, because we asked only a small number of questions in this study. Nevertheless, many students still did not complete the questionnaire. The present results therefore do not reflect the totality of the surveyed classes, and we were able to gain only a partial insight into the students' perspectives on social learning. Also, the design of the study was not ideal. Only one group of older students could be considered as a control group. Finally, social desirability, especially in the positive subgroup, cannot be ruled out. It is possible that some students wanted to please the teacher students whom they liked.

\subsection{Humboldt Meets Ellis?}

Concepts for social learning often show only moderate effects. From a humanistic perspective, we see justifica- 
tion for the explicit teaching of social learning. Social learning by REE can provide the majority of the students with useful insights that they would not otherwise be likely to gain.

Putting von Humboldt in relation to Ellis and wondering how to connect von Humboldt's substantive conceptions of morality with modern concepts raises an interesting view on REE. Von Humboldt emphasized the freedom of the individual, which he did not see as separate from a general education ("Bildung” and "Erziehung"). As a subsidiary of REBT, REE formulated this idea very explicitly so far as in its philosophical view, an individual is a co-designer of his or her existence and works methodically and explicitly in order to augment his or her freedom. REE represents a good way to develop intellectual freedom, which is a good basis of all other acts.

\section{Conclusion}

Teachers need to work harder on the entertaining and educational aspects of teaching. An argumentation for the usefulness of self-technologies such as REBT should be emphasized to a greater degree and might be worth the time investment. Hence, our way to motivate students needs to be revised. On the other hand, it would be profitable to better analyze the quality of teacher-student interactions. The teacher students who tested themselves as teachers by participating in this study, although they were monitored regularly and were given feedback from their teacher educators, showed a large amount of variability in the quality of their actions in the classroom and their interactions with the students (Stoughton, 2007). We are in the process of intensively investigating the impact of this level in our current research. Our results will be incorporated into future implementations of social learning lessons.

Other reasons that might also play a significant role is the cultural affiliation of some students. Naem, Gobbi, Muhammad, and Kingdon (2010), for example, found that Pakistani patients had extreme difficulties talking about feelings and other internal states and did not find REBT to be helpful at all. The authors concluded that the content and methods of REBT must be highly culturally adapted in order to be effective. In our cohort, we had a large proportion of students with parents or grandparents who emigrated from Turkey. It might be the case that cultural norms make it hard for some of these students to talk about emotions and to see some relevance about their knowledge of emotions at all. Knowledge from research on dealing with multicultural classrooms should be suitable incorporated into the teaching process (den Brok \& Levy, 2005; Lo \& Howard, 2009; van Tartwijk, den Brok, Veldman, \& Wubbles, 2008; Weinstein, Tomlinson-Clarke, \& Curran, 2004) and probably some of the teaching methods have to be revised.

\section{Acknowledgements}

This project is a part of the project Identity/Role-Orientation in the "Bund-Länder-Program" and is supported by the German Bundesministery of Education and Research. We are most grateful for Andrea Schlicker who assisted in collecting the data and coordinating the project.

\section{Compliance with Ethical Standards}

The authors declare that they comply with the ethical guidelines.

\section{Conflict of Interest}

The authors have no conflict of interest.

\section{References}

Adomeh, I. O. C. (2006). Fostering Emotional Adjustment among Nigerian Adolescents with Rational Emotive Behaviour Therapy. Educational Research Quarterly, 29, 21-29.

Bernard, M. E. (1990). Rational-Emotive Therapy with Children and Adolescents: Treatment Strategies. School Psychology Review, 19, 294-303.

Blömeke, S. (2006). Globalization and Educational Reform in German Teacher Education. International Journal of Educational Research, 45, 315-324. http://dx.doi.org/10.1016/j.ijer.2007.02.009

Brehm, S. S., \& Brehm, J. W. (1981). Psychological Reactance. A Theory of Freedom and Control. New York, NY: Academic Press. 
Cohen, J. (1988). Statistical Power Analysis for the Behavioural Sciences (2nd ed.). Hillsdale, NJ: Lawrence Erlbaum Associates.

Creswell, J. W. (2014). Educational Research: Planning, Conducting and Evaluating Quantitative and Qualitative Research. Harlow: Pearson.

Den Brok, P., \& Levy, J. (2005). Teacher-Student Relationships in Multicultural Classes: Reviewing the Past, Preparing the Future. International Journal of Educational Research, 43, 72-88. http://dx.doi.org/10.1016/j.ijer.2006.03.007

DiGiuseppe, R., \& Bernard, M. E. (1990). The Application of Rational-Emotive Theory and Therapy to School-Aged Children. School Psychology Review, 19, 268-286.

Donovan, J. J., \& Radosevich, D. J. (1998). The Moderating Role of Goal Commitment on the Goal Difficulty-Performance Relationship: A Meta-Analytic Review and Critical Reanalysis. Journal of Applied Psychology, 83, 308-315. http://dx.doi.org/10.1037/0021-9010.83.2.308

Donovan, J. J., \& Radosevich, D. J. (1999). A Meta-Analytic Review of the Distribution of Practice Effect: Now You See It, Now You Don’t. Journal of Applied Psychology, 84, 308-315. http://dx.doi.org/10.1037/0021-9010.84.5.795

Dryden, W. (2012). Flexibility and Passionate Non-Extremism versus Absolutism and Extremism: Teaching the Basics of REBT Theory and Showing Its Wider Application. Journal of Rational-Emotive \& Cognitive-Behavior Therapy, $30,38-51$. http://dx.doi.org/10.1007/s10942-010-0119-8

Duval, T. S., \& Silvia, P. J. (2009). Self-Awareness, Probability of Improvement, and the Self-Serving Bias. Journal of Personality and Social Psychology, 82, 49-61. http://dx.doi.org/10.1037/0022-3514.82.1.49

Ellis, A. (1994). Reason and Emotion in Psychotherapy. New York: Birch Lane Press.

Flanagan, R., Korrie, A., \& Henry, D. J. (2010). The Impact of Anger Management Treatment and Rational Emotive Behavior Therapy in a Public School Setting on Social Skills, Anger Management, and Depression. Journal of Rational-Emotive \& Cognitive-Behavior Therapy, 28, 87-99. http://dx.doi.org/10.1007/s10942-009-0102-4

Fleming, J. L., Mackrain, M., \& LeBuffe, P.A. (2013). Caring for the Caregiver: Promoting the Resilience of Teachers. In S. Goldstein, \& R. B. Brooks (Eds.), Handbook of Resilience in Children (2nd ed., pp. 349-370). New York: Springer. http://dx.doi.org/10.1007/978-1-4614-3661-4_22

Garcia, E. J., \& Pellegrini, N. (1974). Homer the Homely Hound Dog. New York: Institute for Rational Living, Inc.

Gonzalez, J. E., Nelson, J. R., Gutkin, T. B., Saunders, A., Galloway, A., \& Shwery, C. S. (2004). Rational Emotive Therapy with Children and Adolescents: A Meta-Analysis. Journal of Emotional and Behavioral Disorders, 12, 222-235. http://dx.doi.org/10.1177/10634266040120040301

Haep, A., Steins, G., \& Wilde, J. (2012). Soziales Lernen Sekundarstufe I (Social Learning Secondary School I). Donauwörth: Auer.

Hamre, B. K., \& Pianta, R. C. (2001). Early Teacher-Child Relationships and the Trajectory of Children's School Outcomes through Eighth Grade. Child Development, 72, 625-638. http://dx.doi.org/10.1111/1467-8624.00301

Hamre, B. K., \& Pianta, R. C. (2005). Can Instructional and Emotional Support in the First-Grade Classroom Make a Difference for Children at Risk of School Failure? Child Development, 76, 949-967. http://dx.doi.org/10.1111/j.1467-8624.2005.00889.x

Hatfield, E., Cacioppo, J. T., \& Rapson, R. L. (1994). Emotional Contagion. Paris: Cambridge University Press.

Hattie, J. (2009). Visible Learning. A Synthesis of over 800 Meta-Analyses Relating to Achievement. New York: Routledge.

Higgins, E. T. (1987). Self-Discrepancy: A Theory Relating Self and Affect. Psychological Review, 94, 319-340. http://dx.doi.org/10.1037/0033-295X.94.3.319

Kachman, D. J., \& Mazer, G. E. (1990). Effects of Rational Emotive Education on the Rationality, Neuroticism and Defense Mechanisms of Adolescents. Adolescence, 97, 131-144.

Kirschner, P. A., Sweller, J., \& Clark, R. E. (2006). Why Minimal Guidance during Instruction Does Not Work: An Analysis of the Failure of Constructivist, Discovery, Problem-Based, Experiential, and Inquiry-Based Teaching. Educational Psychologist, 4, 75-86. http://dx.doi.org/10.1207/s15326985ep4102_1

Knaus, W. (1974). Rational-Emotive Education: A Manual for Elementary School Teachers. New York: Institute for Rational Living.

Liew, J., Chen, Q., \& Hughes, J.N. (2010). Child Effortful Control, Teacher-Student-Relationships, and Achievement in Academically At-Risk Children: Additive and Interactive Effects. Early Childhood Research Quarterly, 25, 51-64. http://dx.doi.org/10.1016/j.ecresq.2009.07.005

Lo, A., \& Howard, K. M. (2009). Mobilizing Respect and Politeness in Classrooms. Linguistics and Education, 20, $211-216$. http://dx.doi.org/10.1016/j.linged.2009.07.001

Naem, F., Gobbi, M., Ayus, M., \& Kingdon, D. (2010). Psychologists Experience of Cognitive Behaviour Therapy in a De- 
veloping Country: A Qualitative Study from Pakistan. International Journal of Mental Health Systems, 4, 2. http://dx.doi.org/10.1186/1752-4458-4-2

Patton, M. Q. (2002). Qualitative Research \& Evaluation Methods (3th ed.). London: Sage Publications.

Rushton, S. P. (2000). Student Teacher Efficacy in Inner-City Schools. The Urban Review, 32, 365-383. http://dx.doi.org/10.1023/A:1026459809392

Sapp, M. (1996). Irrational Beliefs That Can Lead to Academic Failure for African American Middle School Students Who Are Academically At-Risk. Journal of Rational-Emotive \& Cognitive-Behavior Therapy, 14, 123-134. http://dx.doi.org/10.1007/BF02238186

Shannon, H. D., \& Allen, T. W. (1998). The Effectiveness of a REBT Training Program in Increasing the Performance of High School Students in Mathematics. Journal of Rational-Emotive \& Cognitive-Behavior Therapy, 16, 197-209. http://dx.doi.org/10.1023/A:1024963131417

Sharp, S. R., \& McCallum, R. S. (2005). A Rational Emotive Behavioral Approach to Improve Anger Management and Reduce Office Referrals in Middle School Children: A Formative Investigation and Evaluation. Journal of Applied School Psychology, 21, 39-66. http://dx.doi.org/10.1300/J370v21n01_03

Solomon, D., Battistich, V., Watson, M., Schaps, E., \& Lewis, C. (2000). A Six-District Study of Educational-Change: Direct and Mediated Effects of the Child Development Project. Social Psychology of Education, 4, 3-51. http://dx.doi.org/10.1023/A:1009609606692

Spitta, D. (2006). Menschenbildung und Staat. Das Bildungsideal Wilhelm von Humboldts angesichts der Kritik des Humanismus (Human Education and State. The Educational Ideal of Wilhelm von Humboldt, Given the Criticism of Humanism). Stuttgart: Mayer.

Steins, G. (2014). Sozialpsychologie des Schulalltags. Band I: Grundlagen und Anwendungen (Social Psychology of School. Volume I: Foundations and Applications). Lengerich: Pabst Science Publishers.

Stoughton, E. H. (2007). "How Will I Get Them to Behave?”: Pre-Service Teachers Reflect on Classroom Management. Teaching and Teacher Education, 23, 1024-1037. http://dx.doi.org/10.1016/j.tate.2006.05.001

Trip, S., Vernon, A., \& McMahon, J. (2007). Effectiveness of Rational-Emotive Education: A Quantitative Meta-Analytical Study. Journal of Cognitive and Behavioral Psychotherapies, 7, 81-93.

Vaida, S., Kallay, E., \& Opre, A. (2008). Counseling in Schools. A Rational Emotive Behavior Therapy (REBT) Based Intervention. A Pilot Study. Cognition, Brain, Behavior: An Interdisciplinary Journal, 12, 57-69.

van Tartwijk, J., den Brok, P., Veldman, I., \& Wubbels, T. (2008). Teachers’ Practical Knowledge about Classroom Management in Multicultural Classrooms. Teaching and Teacher Education, 25, 453-460. http://dx.doi.org/10.1016/j.tate.2008.09.005

Vernon, A. (1996). Counseling Children and Adolescents: Rational Emotive Behavior Therapy and Humanism. Journal of Humanistic Education and Development, 35, 120-127. http://dx.doi.org/10.1002/j.2164-4683.1996.tb00361.x

Vernon, A. (2002). What Works When with Children and Adolescents: A Handbook of Individual Counseling Techniques. Champaign, IL: Research Press.

von Humboldt, W. (1809). Rechenschaftsbericht an den König. In A. Flitner, \& K. Giel (Eds.), Wilhelm von Humboldt. Werke in fünf Bänden (1960-81, Band IV, S. 218). Stuttgart. (Annual Report to the King. Works In five Volumes)

Waters, V. (1980). Rational Stories for Children. New York: Institute for Rational Emotive Therapy.

Weinstein, C. S., Tomlinson-Clarke, S., \& Curran, M. (2004). Toward a Conception of Culturally Responsive Classroom Management. Journal of Teacher Education, 55, 25-38. http://dx.doi.org/10.1177/0022487103259812

Wilde, J. (1997). Hot Stuff to Help Kids Chill out. New York: Institute for Rational Living. 